\title{
What is Computer Science? Outline for a project.
}

\author{
Camille Akmut
}

\begin{abstract}
In a series of 10 propositions, we form a project to guide the development of a (real) computer science, and simultaneously (real) history and sociology of that same discipline, for us, and for future generations.
\end{abstract}




\section{Introduction}

This thesis of ours - computer science is a social science - is no mere intellectual trick or an act of academic bravado. It has real, practical, urgent applications, and meanings.

Let us explain how :

We must do all we can - as computer scientists, as social scientists, as historians, and all the others - to contribute to the definition of this new discipline, which is bound to play such an important and big role in, and on our societies (to come).

If we do not define computer science, it will define us. They - who do not share our social ideals - will define it, and define us, in a way that escapes us, and as a way of consequence.

The technological transformations that our societies are undergoing, which are so great and perhaps without antecedent in all of human history, and cannot in any way be understated contrary to the naive notions of a certain historical-political economist, are here to stay.

(The only plausible way for them to disappear would be if we, our civilization disappeared alongside it.)

Their effects can only be expected, and are bound to become ever, and ever greater on (all of) our lives, in the future.

"They who rob us of our dreams, rob us of our lives" wrote Virginia Woolf at the beginning of the last century.

Our times are ours - though, and only if we make them ours.

To the question "What is computer science?", we will answer again and again: Computer science is a social science.

There can be no doubt about this.

If we do not define it, it will define us (definir) - and perhaps destroy us too (finir) ... 


\section{1 "What is computer science?" 10 propo- sitions}

1. Computer science is a social science.

2. The old question "What is computer science?", which, as we know, was so defining for the beginnings of computer science as a constituted discipline in the 1960s, we argue, has lost its old decorum of defended and argued scientificity against neighboring disciplines - it is now a science with no one left to doubt it. Hence :

3. Instead, the question "What is computer science?", as for our times, and as we can only live in them, has shifted to become all about the responsibility and the identity - certainly defended, and argued - of our, or perhaps we should say their computer scientists.

4. Computer science is, by any standards, including of the history of science, an extremely young and immature discipline, science.

5. Computer science, this extremely young and immature discipline, does not know where it comes from, and hence it does not know where it goes. 6. We must define computer science, otherwise it will define us.

7. They, who do not share our social ideals, and visions of society, will define it for us, without us, against us.

8. Language constitutes the limits of our world, and our thoughts, it has been used to define us, in science, and outside. We must not let it, them define computer science - this so important science - too.

9. Our - their - current computer scientists are at best third-generation scientists. They certainly have no idea where they are going, or who they are, or who they could be. Least, who they ought to be. (They are the pioneers and temporary scientists of their age, sellers and believers of many dreams and promises.)

10. The new computer scientists are social scientists. (Social scientists are the new computer scientists, and computer scientists are the new social scientists.) 
Series (1) : "the social conditions of computer science and technology".

—. 2018 [2017]. "Social conditions of outstanding contributions to computer science : a prosopography of Turing Award laureates (1966-2016). Draft".

—. 2019. "Minerva and Virgil a program (Notes on Karpathy et al. 2014)".

-. 2019b. "A User-Defined Web. And, on Systems modification in general."

-. 2019c. "Notes on the Freedom Tower. Current issues in Networking (mesh).'

—. 2019d. "Hackers Revisited : the "original "hackers"". Clever solutions, political acts."

—. 2019e. "Ensuring the integrity of research in the Age of open access. A proposal : hashing + public-key cryptography signing."

—. 2019f. "When doing good pays : A first research into the remuneration practices of non-profit executives (particularly the IT sector)."

-. 2019g. " "Not just a HR trend". Behind the curtains of diversity : a statistical analysis of role distribution and hiring practices at a technology company."

—. 2019h. "The perfect philosophy for the perfect generation. (Effective Altruism : everywhere but at home.)"

—. 2019i. "The Reinvention of Our Language. "material" = woman."

—. 2019j. "The lonely death of Aaron, the cowards at MIT."

—. 2019k. "The new "Uncle Tom"s of Our New Media."

—. 20191. "The History of Computer Science and Technology. Reflection of a reflection : a (peer) review."

—. 2019m. "We praise our heroes : Notes, translation of "The School of Vienna at Prague" by Jean Cavailles. - and the limits of our world."

—. 2019n. "You Are Not Alone : Memories of Paul Veyne." (annex)

Series (2) : What is Computer Science? The two crises of computer science. (On the responsibility of computer scientists.)

-. 2019o. "The Libertarian roots of the EFF."

—. 2019p. "Computer science is a social science."

—. 2019q. "What is Computer Science? Outline for a project." 